\title{
Electrodeposition of Silver Dendritic-Graphene Composite Film for Photocatalytic Application
}

\author{
Jiliang Xie ${ }^{1,2, *}$, Yanxia Zeng ${ }^{2}$, Xujie Yang ${ }^{1}$ and Xingyou Xu ${ }^{1,3}$ \\ ${ }^{1}$ Chemical Engineering Institute, Nanjing University of Science and Technology Nanjing, 210094, \\ P.R. China \\ 2 Jiangsu Marine Resources Development Research Institute, Lianyungang 222001, P.R. China \\ ${ }^{3}$ School of Chemical Engineering, Huaihai Institute of Technology, Lianyungang 222005, P.R. China \\ *E-mail: jiliangxie_nust3@foxmail.com
}

doi: $10.20964 / 2017.03 .49$

Received: 5 December 2016 / Accepted: 18 January 2017 / Published: 12 February 2017

\begin{abstract}
In this work, a facile one-step electro-deposition approach was reported to synthesize the silver dendritic structure through the multi-walled carbon nanotube (MWCNT) dispersed in AgNO3 solution which was modified with graphene oxide (GO). Scanning electron microscopy was conducted, which demonstrated that the as-synthesized silver material exhibited a well-defined dendritic structure. Besides, according to XRD measurements, the silver was found to be in the cubic phase. GO was demonstrated to be present in silver dendrites through UV-Vis spectroscopy, where GO was electrochemically reduced during the process of silver-deposition. However, based on the preliminary performance test, the pure Ag exhibited a remarkably poor photocatalytic activity, whereas a considerable photocatalytic capacity was observed with the hydrids.
\end{abstract}

Keywords: One-step electro-deposition; Silver dendrites; Graphene oxide;Photocatalysis; Multiwalled carbon nanotube

\section{$\underline{\text { FULL TEXT }}$}

(C) 2017 The Authors. Published by ESG (www.electrochemsci.org). This article is an open access article distributed under the terms and conditions of the Creative Commons Attribution license (http://creativecommons.org/licenses/by/4.0/). 